\title{
Anomalous Connection of the Left Pulmonary Vein to the Coronary Sinus With Intact Atrial Septum in a Young Woman
}

Xianfeng Cheng ( $\sim$ chengxianfeng210@163.com )

Department of Cardiovascular Surgery, Weifang People's Hospital, Weifang, China

\section{Case report}

Keywords: Partial anomalous pulmonary venous connection, intact atrial septum, Coronary Sinus

Posted Date: December 7th, 2020

DOl: https://doi.org/10.21203/rs.3.rs-120541/v1

License: (c) (i) This work is licensed under a Creative Commons Attribution 4.0 International License.

Read Full License 


\section{Abstract}

Background: Left sided Partial anomalous pulmonary venous connection (PAPVC) is a rare congenital abnormal cardiac defect. An intact atrial septum is more uncommon. To our knowledge, connection of the left pulmonary vein (LPV) to the coronary sinus (CS) with intact atrial septum was no previous reported.

Case report: We report an 18-years-old woman who had this rare anomaly. She exhibited no obvious clinical symptoms. An echocardiogram revealed the primary diagnosis and this diagnosis confirmed during operation. This patient underwent a successful surgical repair. Artificial atrial septal defect (ASD) and coronary sinus orifice were inserted into left atrium by patch. postoperative recovery was recuperated.

Conclusion: Given the high risk of developing Congestive heart failure, like many other centers, we advocate for intervention during the preschool age. Surgical techniques depend on the number and location of abnormal veins or veins.

\section{Background}

Partial anomalous pulmonary venous connection (PAPVC) is a relatively rare congenital heart disease in which Partial pulmonary vein blood flows directly Or indirectly into the right atrium [1]. Drainage of partial pulmonary veins to the right atrium can lead to pulmonary hypertension, right atrial enlarge, tricuspid regurgitation and right ventricular dysfunction. The most common presentation(90\%) is accompanied with atrial septal defect (ASD) [2]. When accompanied by atrial septal defect(ASD), the patient may have obvious symptoms and appear in early childhood. However, PAPVC with intact atrial septum, the patient may have no obvious clinical symptoms. PAPVC with an intact atrial septum is rarely reported [3]. For all we know ,anomalous connection of the left pulmonary vein to the coronary Sinus with intact atrial septum have never been reported.

\section{Case Presentation}

A 18-year-old woman was admitted to the local hospital because of heart murmur found by physical examination, where she received a echocardiographic examination, revealing a congenital heart diseas. She was no cyanosis and clinical asymptomatic, however, a grade two systolic murmur on the second and the third left intercostal space was audible. She came to our hospital for further evaluation.

Electrocardiogram showed mild enlargement of right atrium and right ventricle, and the diameter of main pulmonary was also enlarge, but there was no ASD or remarkment tricuspid regurgitation to creat the right ventricular system enlargement(Fig. 1). Further ultrasonic examinat found enlarged coronary sinus measuring $2.31 \mathrm{~cm}$ in diameter with two left pulmonary vein connecting ,and meanwhile, the position of right pulmonary vein was normal(Fig. 2). PAPVC associated without ASD of the left pulmonary vein to the coronary sinus was diagnosed by the cardiac ultrasound and the cardiac surgery was confirmed. 
The patient underwent successful heart surgery and the operation was performed under cardiopulmonary bypass.

During the operation, the opening of the coronary vein was obviously widened, and the probe could reach the left superior and inferior pulmonary veins via the orifice of the coronary vein sinus. There was intact atrial septum and right ventricle and right atrium were mild enlarged. The connection of the right pulmonary veins was normal. An artificial atrial septal defect was formed by cutting the atrial septum. Artificial atrial septal defect and coronary sinus containing left pulmonary vein orifice were patched into left atrial side. Patient recovered smoothly and was discharged 8 days later.

\section{Discussion}

PAPVC is a rare congenital heart disease first reported by Winslow in 1789, Pathological studies show that this disease incidence $0.7 \%$ of the population[4],and research on the incidence of PAPVC has yielded a mixed bag of result, because many patients without clinical symptoms were not captured by the PAPVC rate[5]. Thus the true incidence of PAPVC is slightly higher than expected. Most cases of PAPVC are from the right lung, Only $10-18 \%$ cases of PAPVC from the left pulmonary are reported, PAPVC originating from the right pulmonary occurs ten times more commonly than the connecting veins started from the left lung[4].Few studies of anomalous connection of the left pulmonary vein to the coronary venous sinus have been reported[6]. And meanwhile, PAPVC presented with ASD was reported in $80 \%-90 \%$ of cases[1].Isolated PAPVC associated without ASD have been rarely reported. Additionally, to our knowledge, left pulmonary vein draining into the coronary venous sinus with intact atrial septum have not been reported at present .

The appearance of the clinical symptoms usually occurs in PAPVC during adulthood[2]. The pathophysiology of PAPVC is alike to the left-to-right shunt in simple ASD, Congestive heart failure caused by PAPVC depends on how many pulmonary veins abnormally connect to the right atrium. Imaging examinations to diagnose PAPVC consist of chest plain films, CT and MRI, cardiac catheterization[7]. Doppler echocardiography reveals the trend and distribution of pulmonary veins. therefore, cardiac uhrasonography is becoming the simple and effective method of the PAPVC.

Those with PAPVC without symptoms should have a physical exam and an echocardiogram once a year. Patients with the symptoms of heart failure can be controlled with after load reduction, beta blockers ,diuretics, and cardiac glycosides. The surgical repair was the most effective treatment to PAPVC[6]. The preschool age is the optimal time for intervention. Surgical techniques depend on the number and location of abnormal veins or veins.

\section{Conclusion}

In view of the above and many other similar reports, we recommend timely surgical treatment to correct the deformity, which is the least risky and has the best results. 


\section{Abbreviations}

PAPVC

Partial anomalous pulmonary venous connection; LPV:left pulmonary vein; CS:coronary sinus; ASD:Artificial atrial septal defect.

\section{Declarations}

\section{Acknowledgements}

We are grateful of the support from Shandong Provincial Hospital.

\section{Authors' contributions}

XC-data collection, curation, concept, design of initial and final manuscript, All authors read and approved the final manuscript.

\section{Funding}

No financial support.

\section{Availability of data and materials}

Available on appropriate request from author.

\section{Ethics approval and consent to participate}

Hospital Ethics committee approved publication.

\section{Consent for publication}

Patient was informed and written consent obtained.

\section{Competing interest}

The authors declare that they have no competing interests.

\section{References}

1. Elami A, Rein AJ, Preminger TJ, Milgalter E. Tetralogy of Fallot, absent pulmonary valve, partial anomalous pulmonary venous return and coarc- tation of the aorta.

2. Int J Cardiol 1995;52:203(6).

3. Broy C, Bennett S. Partial anomalous pulmonary venous return. Mil Med 2008;173:523(4).

4. Zhang Z, Zhang L, Xie F,Xie M ,et al.Echocardiographic diagnosis of anomalous pulmonary venous connections. Medicine (Baltimore).2016 Nov ;95(44):e5389. 
5. Mei FY,Bai ZX, Hu ZB, Cui Y,et al. Rare association of two cardiovascular malformations successfully corrected in a single surgery: a case report. Journal of Cardiothoracic Surgery(2017) 12:58 DOI 10.1186/s13019-017-0619-z.

6. Kim YN, Cho HJ,Cho YK, Ma JS. Partial anomalous pulmonary venous connection with intact atrial septum in a child with ventricular septal defect: a case report. Korean J Pediatr.2012 Jan ;55(1):24-8.

7. Ho CL, Tsai IC, Lin MC, Fu YC, et al.Anomalous Connection of the Right Pulmonary Vein to the Coronary Sinus in a Young Infant. Pediatr Neonatol.2014 Oct ;55(5):407-9.

8. Clarke NS, Murthy RA, Guleserian KJ .Persistent Left Superior Vena Cava: Incidence and Management in Patients Undergoing Repair of Partial Anomalous Pulmonary Venous Connection. World J Pediatr Congenit Heart Surg.2017 07 ;8(4):440-444.

\section{Figures}
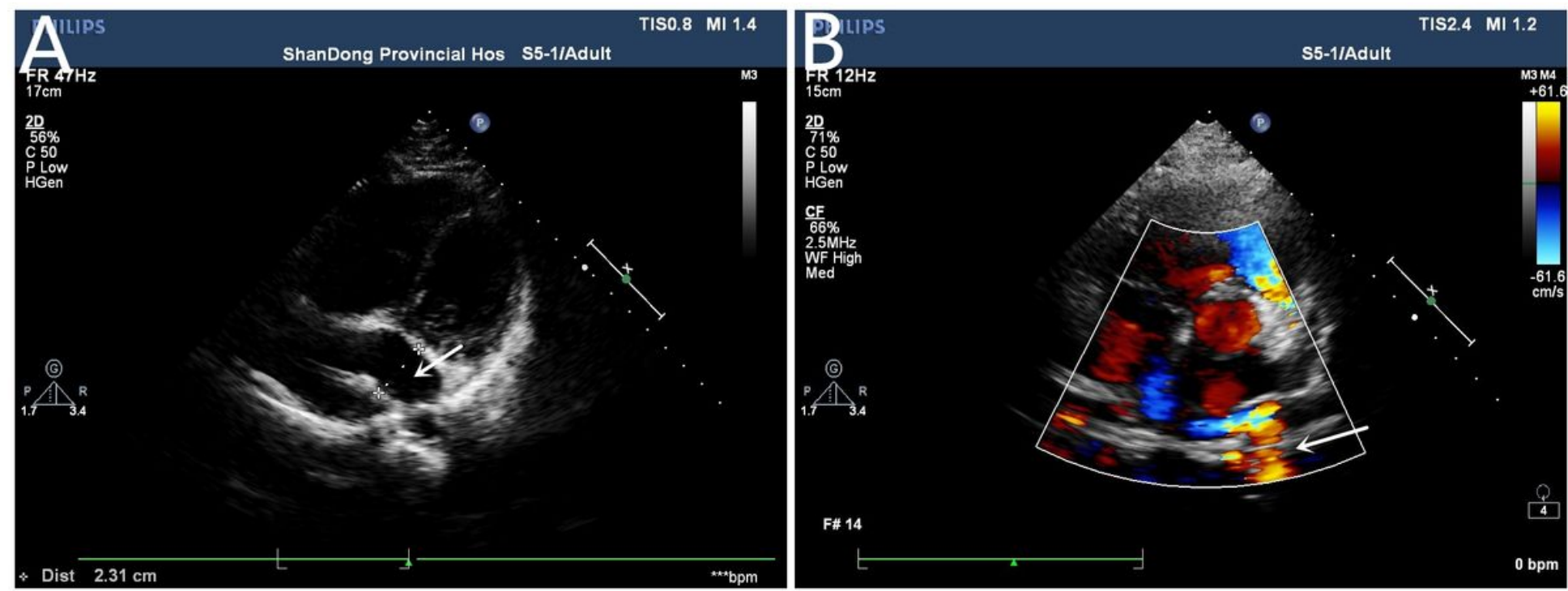

\section{Figure 1}

The image analysis by Echocardiography. (A)displaying the diameter of main pulmonary is enlarge(arrows).(B) Demonstrating an intact atrial septum between the right and left atria(arrows). 


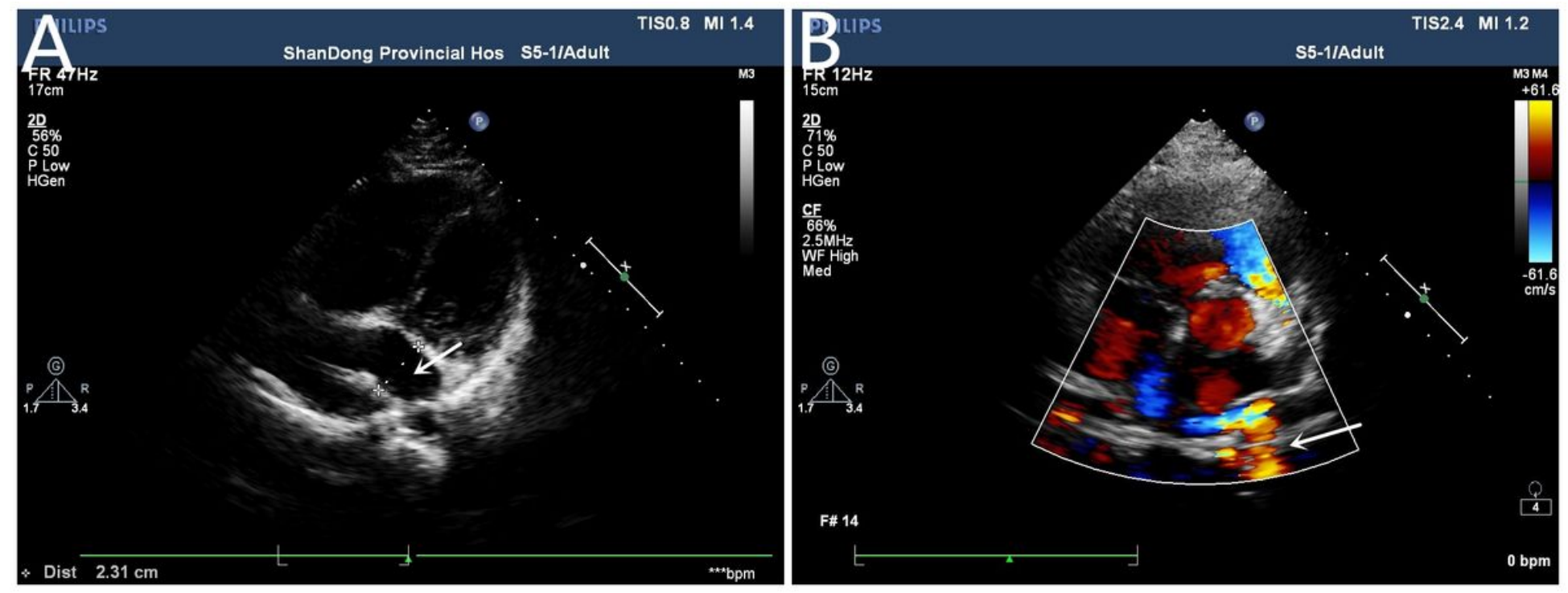

\section{Figure 1}

The image analysis by Echocardiography. (A)displaying the diameter of main pulmonary is enlarge(arrows).(B) Demonstrating an intact atrial septum between the right and left atria(arrows).

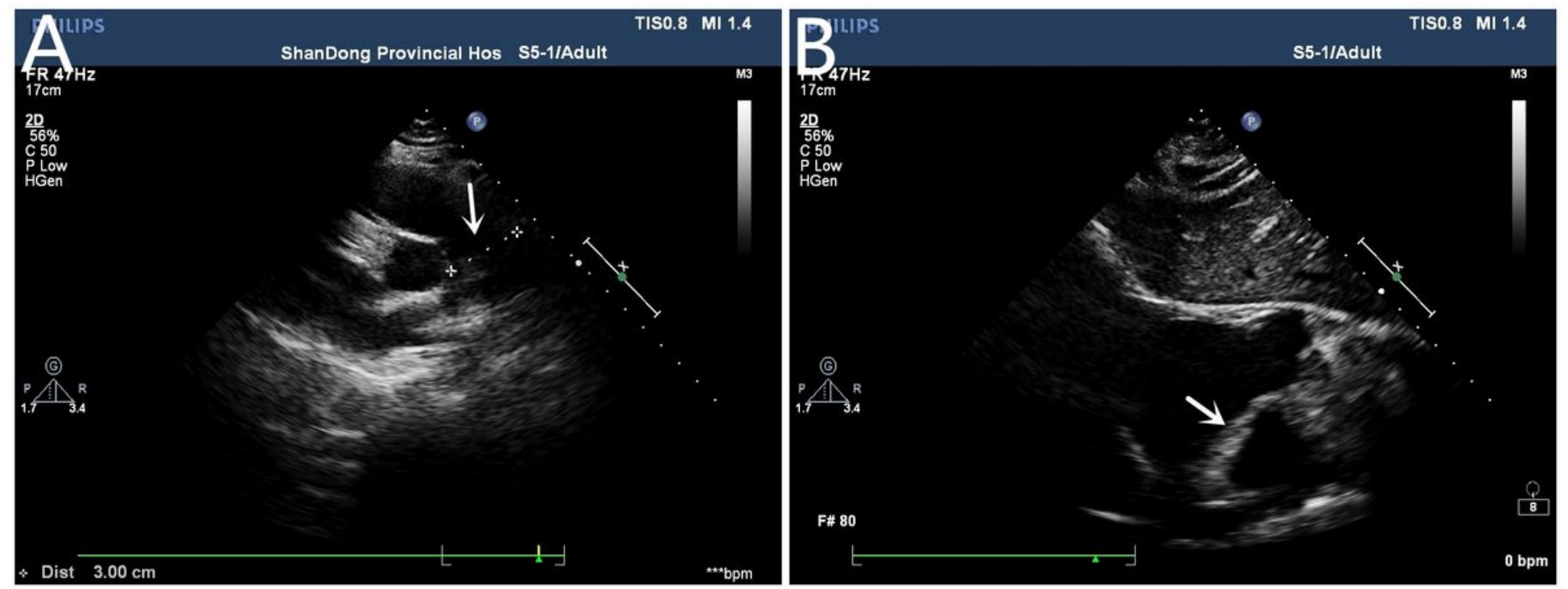

\section{Figure 2}

Further analysis by Echocardiography. (A) showing the coronary sinus is widened(arrows).(B) Illustrating anomalous connection of the left pulmonary vein to the coronary Sinus (arrows). 


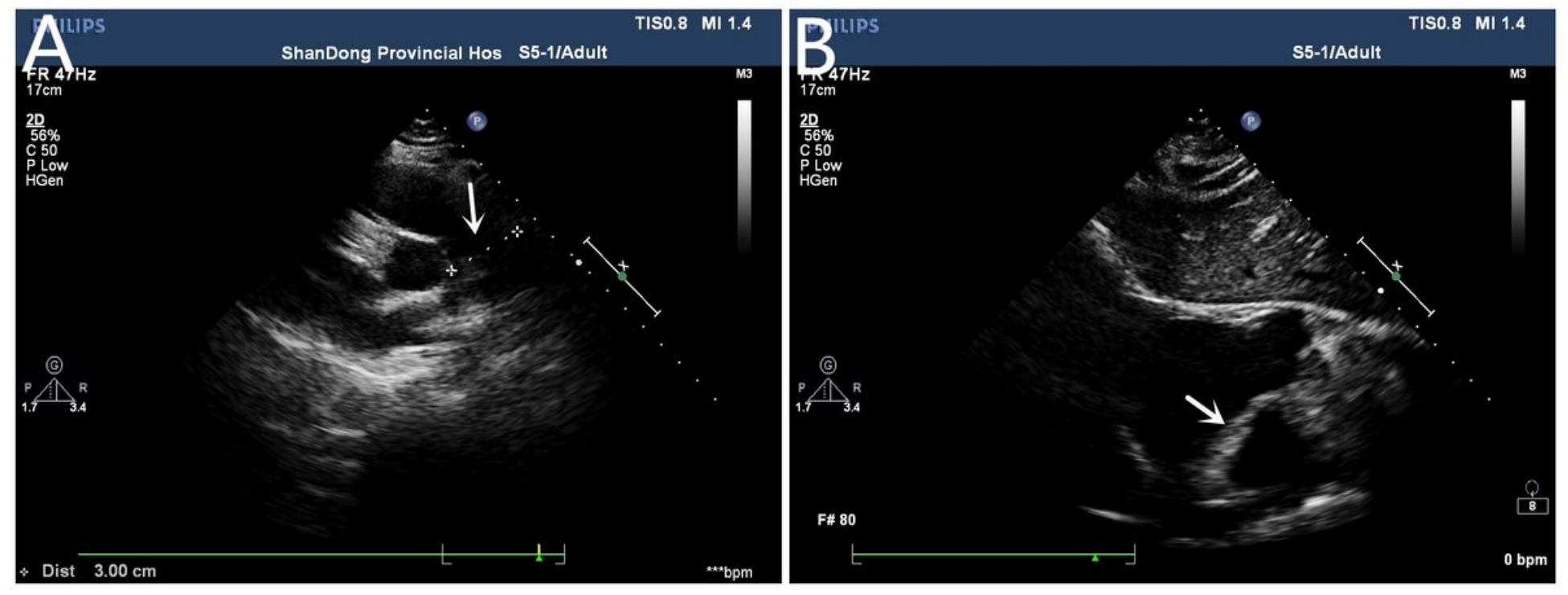

Figure 2

Further analysis by Echocardiography. (A) showing the coronary sinus is widened(arrows).(B) Illustrating anomalous connection of the left pulmonary vein to the coronary Sinus (arrows).

\section{Supplementary Files}

This is a list of supplementary files associated with this preprint. Click to download.

- CAREchecklistEnglish2013.pdf

- CAREchecklistEnglish2013.pdf 